\title{
POTENCIAL ENDÊMICO DA ESQUISTOSSOMOSE PARA O ESTADO DE RONDỐNIA, BRASIL
}

\begin{abstract}
Carlos E. A. Coimbra Jr.* Ricardo Ventura Santos** Luiz Smanio Neto*

COIMBRA Jr., C. E. A. et al. Potencial endêmico da esquistossomose para o Estado de Rondônia, Brasil. Rev. Saúde públ., S. Paulo, 18: 510-15, 1984.

RESUMO: Foram realizadas coletas malacológicas na cidade de Porto Velho, Rondônia (Brasil), visando conhecer a distribuição das espécies de Biomphalaria e a caracterização ecológica dos criadouros. Como único representante deste gênero, foi encontrada e espécie $B$, ama. zonica em valetas para captação de águas pluviais e esgotos domésticos na cidade. Três mil caramujos foram submetidos à pesquisa de cercárias, com resultados negativos. São apresentados os casos de esquistossomose notificados na Secretaria da Saúde de Rondônia para os anos de 1982 e 1983 nos munićpios sob influência da rodovia BR-364. Discute-se a importância epidemiológica destes achados no estabelecimento de focos ativos de transmissão da esquistossomose em Rondônia.
\end{abstract}

UNITERMOS:Esquistossomose, ocorrência. Biomphalaria amazonica. Epidemiologia, Rondônia, Brasil.

\section{INTRODUÇÃO}

A esquistossomose é uma endemia cuja ocorrência está intimamente ligada às condições de vida da população. No Brasil, sua expansão para áreas ainda indenes tem ocorrido principalmente através de movimentos migratórios procedentes de áreas endêmicas.

No contexto nacional e, em particular na Amazônia, o Estado de Rondônia destaca-se por apresentar elevados índices migratórios e a mais alta taxa de crescimento demográfico anual, da ordem de $15,8 \%\left(\right.$ IBGE $\left.^{4}\right)$. Quanto à origem desse contingente migratório, recai principalmente nos Estados do Sul e Sudeste brasileiros, e em segundo lugar, no Nordeste.

Nessa população, assentada nos projetos de colonização recém-criados ou inflando os centros urbanos, verifica-se uma característica marcante - a precariedade das condiçōes de habitação e saúde, agravadas pela inexistência de infra-estrutura sanitária adequada.
Dos fatores biológicos de importância na epidemiologia da esquistossomose, tem sido verificada a presença de planorbídeos em diferentes ecótopos, apesar das poucas pesqujsas malacológicas já efetuadas no Estado.

Como se vê, as condições necessárias ao fechamento da cadeia epidemiológica da esquistossomose em Rondônia parecem estar presentes - migrações, populaçס̃es de baixo nível sócio-econômico procedentes de áreas endêmicas, condições de saneamento deficientes e ocorrência de moluscos planorbídeos do gênero Biomphalaria.

Neste trabalho sto apresentados os resultados preliminares das pesquisas malacológicas realizadas na cidade de Porto Velho e em seus arredores, assim como a distribuição e caracterização ecológica dos criadouros. $\mathbf{E}$ também apresentada a casuística da esquistossomose no Estado para os anos de 1982 e

* Do Núcleo de Pesquisa em Saúde, da Secretaria da Saúde de Rondônia - Caixa Postal 1314 - 78.900 - Porto Velho, RO - Brasil.

** Estagiário no Núcleo de Pesquisa em Saúde de Rondônia. Estudante de Ciências Biológicas da Universidade de Bras llia. 
COIMBRA Jr., C.E.A. et al. Potencial endêmico da esquistossomose para o Estado de Rondônia, Brasil. Rev. Saúde públ., S. Paulo, 18:510-15, 1984.

1983, nos municípios localizados ao longo da BR-364 (rodovia Cuiabá - Porto Veiho), ou sob sua influência. Finalmente, discute-se a importância epidemiológica desses achados no estabelecimento de focos ativos de transmissão da esquistossose em Rondônia.

\section{MATERIAL E MÉTODOS}

As coletas malacológicas foram realizadas na cidade de Porto Velho e cercanias, nos meses de janeiro a fevereiro de 1984, em ecótopos naturais (brejos e igarapés) e em coleções aquáticas formadas artificialmente como decorrência do processo de urbanização (valetas para drenagem de águas pluviais e esgotos domésticos).

Todos os caramujos colecionados foram expostos à luz natural para pesquisa de cercárias. De modo a permitir a realização de estudos taxonômicos, cerca de 10 exemplares coletados em diferentes pontos da cidade tiveram suas partes moles removidas da concha e fixadas em álcool $70 \%$.

Para a pesquisa de casos humanos de esquistossomose, para os anos de 1982 e 1983 , foram consultados os arquivos do Departamento de Epidemiologia da Secretaria de Estado da Saúde de Rondônia.

\section{RESULTADOS}

Os resultados das pesquisas malacológicas em Porto Velho revelaram a ocorrência de Biomphalaria amazonica como único representante desse gênero nos criadouros da cidade. No entanto, outros gêneros de mo. luscos aquáticos também foram observados, a saber: Physa e Pomacea.O mapa (Fig. 1) permite a visualização da distribuição da $B$. amazonica em Porto Velho.

Quanto à pesquisa de cercárias, dos 3.000 exemplares de Biomphalaria amazonica coletados em diferentes pontos da cidade, todos foram negativos.

Os principais criadouros para a $B$. amazo. nica mostraram ser as valas para captação de águas pluviais e esgotos domésticos existen. tes ao longo de inúmeras ruas da cidade (Fig. 2 ). Nessas valetas observou-se copiosa vege- tação aquática constituída principalmente por espécies de Eichkornia e Pontederia (Pontederiacea), Pistia e Caladium (Araceae) e Cypereus (Cyperaceae), que colonizam as margens e, em muitos casos, promovem a obstrução das valetas. Os valores de $\mathrm{pH}$ nessas coleções aquáticas oscilaram entre 6 e 7 .

O número de casos notificados de esquistossomose no Estado, para os anos de 1982 e 1983 , pode ser visto na Tabela. O município com maior número de casos notificados foi o de Cacoal (138 em 1982 e 105 em 1983), seguido por Colorado D'Oeste (16 em 1982 e 73 em 1983) e Ji-Paraná (23 em 1982 e 38 em 1983). Os municípios que apresentaram menor número de casos da infecção foram Pimenta Bueno (8 em 1982 e 5 em 1983), Presidente Médici (7 em 1982 e 7 em 1983) e Ariquemes ( 2 em 1982 e 13 em 1983).

\section{DISCUSSÃO}

Na Amazônia, a transmissão da esquistossomose tem se restringido a focos isolados localizados no Estado do Pará, particularmente nos municípios de Belém, Quatipuru e Altamira (Fraiha e Moraes ${ }^{3}$ ). Nestas áreas, as espécies de planorbídeos implicadas na transmissão da parasitose têm sido a Biomphalaria glabrata em Quatipuru (Paraense ${ }^{6}$ ) e B. straminea em Belém e Altamira (Galvão ${ }^{5}$ e Paraense ${ }^{6}$ ).

Quanto à $B$. amazonica, apesar da mesma nunca ter sido responsabilizada como trans. missora da doença em condições naturais, mostrou-se suscetivel ao Schistosoma mansoni experimentalmente, como atestaram Corrêa e Paraense ${ }^{2}$ com moluscos procedentes de Manaus. A ocorrência desta espécie já havia sido assinalada anteriormente em Porto Velho por Paraense ${ }^{6}$, que, ainda no Estado de Rondônia, registrou sua presença na cidade de Guajará-Mirim. A Fig. 1 evidencia a ampla distribuição da espécie na cidade de Porto Velho.

As condições ecológicas das valas que constituem os criadouros de $B$. amazonica em Porto Velho são favoráveis ao deserrolvimento do molusco, haja vista os valores de 
COIMBRA Jr., C.E.A. et al. Potencial endêmico da esquistossomose para o Estado de Rondônia, Brasil. Rev. Saúde públ., S. Paulo, 18: 510-15,1984.

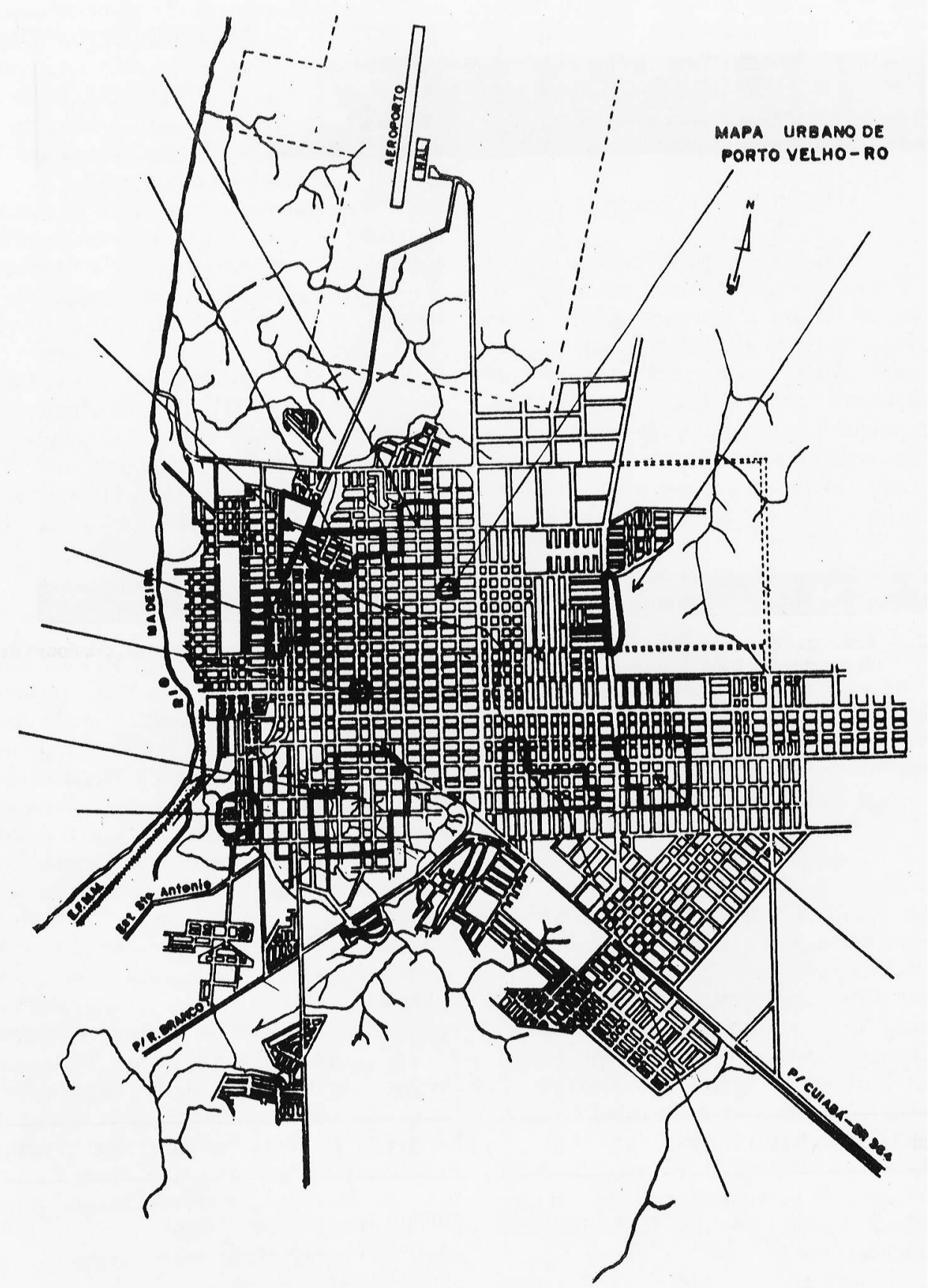

Fig. 1 - Mapa indicando os principais criadouros de Biomphalaria amazonica na cidade de Porto Velho, Rondônia (jan./fev , 1984). 
COIMBRA Jr., C.E.A. et al. Potencial endêmico da esquistossomose para o Estado de Rondônia, Brasil. Rev. Saúde públ., S. Paulo, 18: 510-15, 1984.

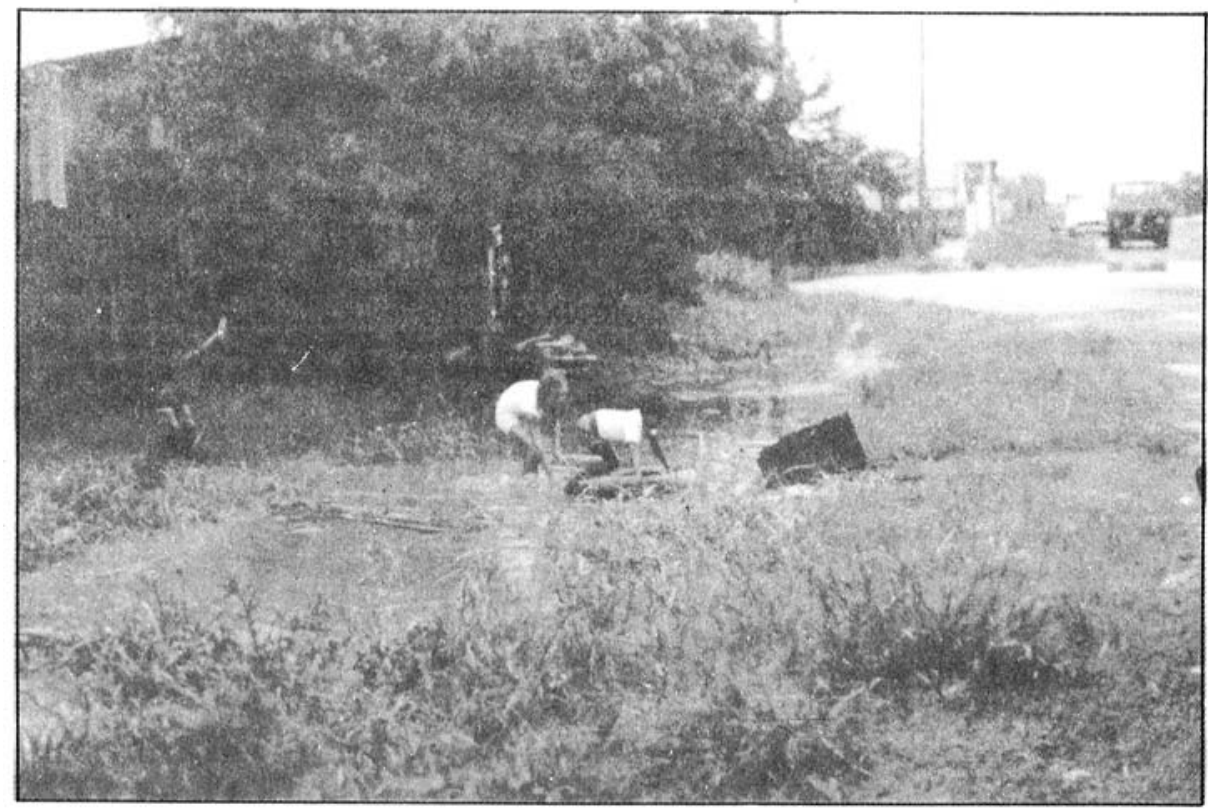

Fig. 2 - Crianças brincando em vala para captação de águas pluviais e esgotos domésticos, criadouro de B. amazonica, logo após uma forte chuva. Porto Velho, RO (jan/1984).

T A B E L A

Casos notificados de esquistossomose nos municípios sob influência da rodovia BR-364 em Rondônia, nos anos de 1982 e 1983.

\begin{tabular}{|c|c|c|c|c|c|c|c|c|c|c|c|c|}
\hline \multirow[b]{2}{*}{ Ano } & \multicolumn{11}{|c|}{ Municípios } & \multirow[b]{2}{*}{ Total } \\
\hline & $\begin{array}{l}\text { Porto } \\
\text { Velho }\end{array}$ & $\begin{array}{l}\text { Arique- } \\
\text { mes }\end{array}$ & Jarú & $\begin{array}{c}\text { Ouro } \\
\text { Preto } \\
\text { D'Oeste }\end{array}$ & $\begin{array}{l}\text { Ji-Pa- } \\
\text { raná }\end{array}$ & $\begin{array}{l}\text { Pres. } \\
\text { Médici }\end{array}$ & Cacoal & $\begin{array}{c}\text { Pi- } \\
\text { menta } \\
\text { Bueno }\end{array}$ & $\begin{array}{l}\text { Espigão } \\
\text { d'Oeste }\end{array}$ & Vilhena & $\begin{array}{l}\text { Colora- } \\
\text { do } \\
\text { d'Oeste }\end{array}$ & \\
\hline $\begin{array}{l}1982 \\
1983\end{array}$ & $\begin{array}{l}29 \\
08\end{array}$ & $\begin{array}{l}02 \\
13\end{array}$ & $\begin{array}{l}14 \\
05\end{array}$ & $\begin{array}{l}04 \\
39\end{array}$ & $\begin{array}{l}23 \\
38\end{array}$ & $\begin{array}{l}07 \\
07\end{array}$ & $\begin{array}{l}138 \\
105\end{array}$ & $\begin{array}{l}08 \\
05\end{array}$ & $\begin{array}{l}15 \\
20\end{array}$ & $\begin{array}{l}12 \\
08\end{array}$ & $\begin{array}{l}16 \\
73\end{array}$ & $\begin{array}{l}268 \\
321\end{array}$ \\
\hline Total & 37 & 15 & 19 & 43 & 61 & 14 & 243 & 13 & 35 & 20 & 89 & 589 \\
\hline
\end{tabular}

$\mathrm{pH}$ verificados (6 a 7), a presença de vegetação aquática, substrato lodoso e pouca ou nenhuma correnteza. Deve-se observar que muitas dessas valetas estão de alguma maneira ligadas a igarapés, de onde provavelmente originam-se os caramujos. Este fato explica a razão pela qual as valetas, que secam durante os meses de verão (junho a agosto), são pron- tamente recolonizadas com as primeiras chuvas, pois, nesses casos, os moluscos poderiam ser levados, através das enxurradas, para as valetas que se ressecaram.

Ainda a respeito da fauna planorbidica do Estado, Paraense ${ }^{6}$ registrou a presença de Biomphalaria occidentalis na cidade de Ouro Preto D'Oeste, distante de Porto Velho cerca 
COIMBRA Jr., C.E.A. et al. Potencial endêmico da esquistossomose para o Estado de Rondônia, Brasil. Rev. Saúde públ., S. Paulo, 18: 510-15, 1984.

de $250 \mathrm{~km}$ ao sul, no eixo da BR-364, e que se tem constituido em importante pólo de atração de migrantes.

A espécie acima não se tem mostrado boa transmissora da esquistossomose, pois os testes de suscetibilidade em laboratório condu. zidos por Paraense e Corrêa ${ }^{8}$ e Coimbra Jr. e Engel $^{1}$ foram negativos. No entanto, como advertem estes últimos autores ${ }^{1}$, esses resultados ainda sto insuficientes para concluir pela impossibilidade da $B$. occidentalis vir a transmitir a doença na região. Para que isso se comprove, diferentes cepas de $S$. mansoni devem ser testadas em moluscos de procedências variadas. Mesmo assim, persistirá a possibilidade de adaptação de cepas de $S$. mansoni às cepas locais de $B$. occidentalis, a exemplo do que observaram Paraense e Corrêa ${ }^{7}$ com $B$. tenagophila do Vale do Rio Paraíba, Estado de São Paulo.

Quanto aos casos de esquistossomose no. tificados em 1982 e 1983, a análise da Tabela não nos permite avaliar com segurança a situação da endemia no Estado, pois o Sistema Estadual de Vigilância Epidemiológica só foi implantado pela Secretaria da Saúde no segundo semestre de 1982. Outro agravante reside na pouca regularidade com que sao enviadas as notificações para a Secretaria da Saúde em Porto Velho, variando muito de acordo com o Município. Somando-se a esses fatores, os hospitais e clínicas particulares não notificam as doenças consideradas de notificação obrigatória e, portanto, muitos casos não são registrados.

Ainda que subnotificados, o número de casos registrados para esse período destaca-se no município de Cacoal, para onde se dirige atualmente a maior leva do contingente migratório que chega a Rondônia. Os municípios de Colorado D’Oeste, Ji-Paraná e Ouro
Preto D'Oeste são também importantes pólos de atração e mostraram-se com elevado número de casos de esquistossomose, quando comparados com os demais.

Quanto à brusca queda do número de casos notificados em Porto Velho (29 em 1982 e 8 em 1983), esse fato pode ser explicado como conseqüência da desativação, por um período de quatro meses, de um importante centro de saúde da capital. As quedas também verificadas nos municípios de Jarú, Pimenta Bueno e Vilhena provavelmente devem-se a falhas no sistema de notificação de casos, ainda não bem consolidado no Estado.

Acreditamos, portanto, que existem em Rondônia os fatores necessários ao estabelecimento de focos de esquistossomose. Nesse sentido, é necessária a realização de estudos epidemiológicos para detectar a procedência dos indivíduos infectados, visando a desco. berta de casos autóctones. Além disso, o aprofundamento dos conhecimentos acerca da fauna malacológica regional, adicionado da execução de testes de suscetibilidade em laboratório das Biomphalaria encontradas frente a diferentes cepas de $S$. mansoni, permitirá determinar com maior margem de segurança o potencial existente em Rondônia para o surgimento de focos de esquistossomose.

\section{AGRADECIMENTOS}

Ao professor Frederico Simões Barbosa, da Escola Nacional de Saúde Pública, Rio de Janeiro, pelas sugestóes emitidas e revisðo dos originais. A Dra. Vera Lúcia G. C. Smanio, da Secretaria de Estado da Saúde de Rondônia, pelas facilidades durante as pesquisas nos arquivos do Departamento de Epidemiologia daquela Secretaria. 
COMMBRA Jr., C.E.A. et al, Potencial endêmico da esquistossomose para o Estado de Rondônia, Brasil. Rev. Saide puibl., S. Paulo, 18: 510-15, 1984.

COIMBRA Jr., C. E. A. et al. [Endemic potential of shistosomiasis for the State of Rondonia, Brazil]. Rev. Saúde públ., S. Paulo, 18: 510-15, 1984.

ABSTRACT: A malacological survey was carried out in the town of Porto Velho, Rondônia, in order to establish the distribution of Biomphalaria species and ecological caracterization of the breeding places. The only species found was $B$. amazonica, occurring in open drainage ditches along streets, for the collection of pluvial water and domestic waste. Three thousand snails were examined for cercariae, with negative results. The cases of schistosomiasis of which the State Health Department was notified during the years 1982 and 1983 in the counties affected by the BR-364 highway, are presented. Finally, the epidemiological importance of these findings in the establishment of active foci of schistosomiasis in Rondonia is discussed.

UNITERMS: Schistosomiasis, occurrence. Biomphalaria amazonica Epidemiology .

\section{REFERENCIAS BIBLIOGRÅFICAS}

1. COIMBRA Jr., C. E. A. \& ENGEL, L. A. Sus cetibilidade de Biomphalaria occidentalis do Acre e Mato Grosso à infecçăo pelo Schistosoma mansoni e sua implicaçăo na epidemiologia da esquistossomose na Amazonia Ocidental, Brasil. Acte amazon., 12: 795-9, 1982.

2. CORREA, L. \& PARAENSE, W. L. Susceptibility of Biomphalaria amazonica to infection with two strains of Schistosoma mansoni. Rev. Inst. Med. trop. S. Paulo, 13: $387-90,1971$.

3.FRAIHA, H. \& MORAES, M. A. P. Esquistossomose. In: Linhares, A. da C., coord. Saúde na Amazónica. 2å ed. Sáo Paulo, Associação Nacional de Programaçáo Econômica e Social, 1983.

4. FUNDAÇÃo IBGE. Censo demogrífico 1980: Rondônia. Rio de Janeiro, 1982.
5. GALVÃO, S. S. Esquistossomose em Belém do Pará. Rev. bras. Malar., 20: 215-24, 1968.

6. PARAENSE, W. L. A survey of planorbid snails in the amazonic region of Brazil. Mem. Inst. Oswaldo Cruz, 78: 343-61, 1982.

7. PARAENSE, W. L. \& CORREA, L. Susceptibility of Australorbis tenagophilus to infection with Schistosoma mansoni. Rev. Inst. Med. trop. S. Paulo, 5: 23-9, 1963.

8. PARAENSE, W. L. CORREA, L. Unsusceptibility of Biomphalaria occidentalis to infection with a strain of Schistosoma mansoni. Mem. Inst. Oswaldo Cruz, 77: 55-8, 1982.

Recebido para publicaço em 14/05/1984. Aprovado para publicą̧̄o em 17/08/1984. 